\title{
Prevalence of Autonomic Dysfunction in Patients with Multiple Sclerosis
}

\author{
Prevalência da Disfunção Autonómica em Doentes com Esclerose Múltipla
}

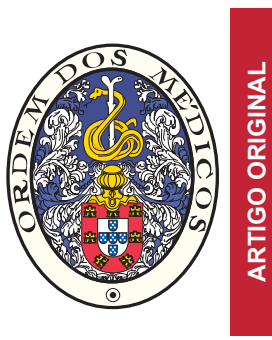

\author{
Bítia VIEIRA ${ }^{1}$, Andreia COSTA ${ }^{2,3}$, Gonçalo VIDEIRA ${ }^{1}$, Maria José SÁ ${ }^{4,5}$, Pedro ABREU 3,4 \\ Acta Med Port 2015 Jan-Feb;28(1):51-55
}

\section{ABSTRACT}

Background: Autonomic nervous system dysfunction is commonly seen in multiple sclerosis patients and should be explored in the routine evaluation. Composite Autonomic Symptom Score questionnaire was validated as a self-assessment instrument of autonomic symptoms.

Objectives: Determine the frequency of autonomic symptoms in multiple sclerosis patients through a Portuguese version of Composite Autonomic Symptom Score; compare questionnaire results between patients and a control group; assess the feasibility of this questionnaire application in multiple sclerosis Portuguese patients.

Material and Methods: This case-control study used a Portuguese translated version of Composite Autonomic Symptom Score to determine the frequency of autonomic symptoms in multiple sclerosis patients.

Results: One-hundred and three relapsing-remitting multiple sclerosis patients - median age 41 years, median disease duration 6 years, median EDSS score 1 - and 80 healthy subjects were included. Alterations in autonomic function were reported in $97.1 \%$ of the cases, with statistical significance in orthostatic intolerance and gastrointestinal domain scores. Nevertheless, the difference between multiple sclerosis patients (41.7\%) without confounding factors that could interfere with autonomic dysfunction (i.e. comorbidities or medications) and controls showed no statistical significance.

Discussion: Our results may be related to the short disease duration, young age and lowdisability status of our patients unaffected by confounding factors. The questionnaire was not designed specifically for multiple sclerosis and it may not be as sensible to early autonomic symptoms as to more severe manifestations.

Conclusions: Further studies are needed to achieve more robust results, validate this questionnaire and assess its application in multiple sclerosis patients in Portugal.

Keywords: Autonomic Nervous System; Multiple Sclerosis; Portugal; Questionnaires.

\section{RESUMO}

Introdução: A disfunção do sistema nervoso autónomo é comum na esclerose múltipla e deveria ser explorada na avaliação de rotina. O questionário Composite Autonomic Symptom Score foi validado como instrumento de auto-avaliação de sintomas autonómicos.

Objetivos: Determinar a frequência de sintomas autonómicos em doentes com esclerose múltipla através de uma versão portuguesa do Composite Autonomic Symptom Score; comparar os resultados do questionário entre um grupo de doentes e um grupo controlo; avaliar a viabilidade da aplicação deste questionário em doentes portugueses.

Material e Métodos: Neste estudo caso-controlo utilizou-se uma tradução portuguesa do questionário para determinar a frequência de sintomas autonómicos em doentes com esclerose múltipla.

Resultados: Incluíram-se 103 doentes com esclerose múltipla surto-remissão - idade média 41 anos, mediana de duração da doença 6 anos, EDSS médio 1 - e 80 indivíduos saudáveis. Dos doentes, 97,1\% tinham alterações da função autonómica, com significado estatístico nos domínios intolerância ortostática e gastrointestinal. Não encontramos diferenças estatísticas entre doentes (41,7\%) sem fatores de confundimento que podiam interferir com a função autonómica (i.e. comorbilidades ou medicações) e o grupo controlo. Discussão: Os resultados obtidos podem estar relacionados com a curta duração de doença, idade jovem e baixo grau de incapacidade dos doentes sem fatores de confundimento. O questionário utilizado não foi desenhado especificamente para a esclerose múltipla e pode não ser tão sensível para sintomas autonómicos mais precoces como para manifestações mais graves da doença.

Conclusões: Outros estudos serão necessários para obter resultados mais robustos, validar este questionário e avaliar a sua aplicação nos doentes portugueses.

Palavras-chave: Esclerose Múltipla; Portugal; Questionários; Sistema Nervoso Autónomo.

\section{BACKGROUND}

Multiple sclerosis (MS) is a chronic demyelinating, inflammatory and autoimmune disease of the central nervous system. During the dissemination of the disease in time and space the autonomic nervous system is inevitably injured. ${ }^{1}$ The autonomic nervous system dysfunction (ANSD) is commonly seen in patients with MS and is

characterized by bladder and gastrointestinal disturbances, sexual dysfunction, abnormalities in cardiovascular function and sudomotor disorders. ${ }^{1-7}$ These symptoms may have a significant impact in patients' quality of life and should be explored as part of the routine evaluation. ${ }^{1-5,8}$ Neurological disability assessed by Expanded Disability Status Scale

\footnotetext{
1. Faculdade de Medicina. Universidade do Porto. Porto. Portugal.

2. Serviço de Neurologia. Centro Hospitalar de S. João. Porto. Portugal.

3. Departamento de Neurociências e Saúde Mental. Faculdade de Medicina. Universidade do Porto. Porto. Portugal.

4. Serviço de Neurologia. Centro Hospitalar de S. João. Porto. Portugal

5. Faculdade das Ciências da Saúde. Universidade Fernando Pessoa. Porto. Portugal.

Recebido: 06 de Junho de 2014 - Aceite: 02 de Novembro de 2014 | Copyright @ Ordem dos Médicos 2015
} 
(EDSS) focuses mainly on the somatic nervous system and undervalues the role of autonomic failure, only taking into account bladder and bowel dysfunction. ${ }^{1,3,4}$ Hence, autonomic symptoms can be easily overlooked by exclusive EDSS follow-up. ${ }^{7}$ Several studies have suggested the use of questionnaires to evaluate ANSD in order to improve disease management. ${ }^{2,7-11}$ Recently, the questionnaire Composite Autonomic Symptom Score (COMPASS $31)^{12}$ was developed and validated as a self-assessment instrument of autonomic symptoms and function, based on the well-established Autonomic Symptom Profile (ASP). ${ }^{8}$ Although not specifically designed for MS, this questionnaire is up-to-date, broadly applicable, easy to administer and based on a scientific approach. ${ }^{12}$

\section{OBJECTIVES}

The primary aim of this study was to determine the frequency of autonomic symptoms in a cohort of relapsingremitting MS (RRMS) patients of our Outpatient Clinic through a Portuguese version of COMPASS 31. The secondary aims were i) to compare results between MS patients and a control group and ii) to assess the feasibility of this questionnaire application in MS Portuguese patients.

\section{MATERIAL AND METHODS Study design}

In this case-control study, 105 MS patients were randomly selected from all those followed on MS Outpatient Clinic of the Centro Hospitalar de S. João. Inclusion criteria for participation were definitive diagnosis of RRMS (according to the McDonald criteria) ${ }^{13}$ and age above 18 years old. Besides demographics and MS history data, patient's information about confounding factors, i.e. comorbidities (heart disease, diabetes mellitus, renal failure, liver failure, peripheral neuropathy) or medications (anticholinergics, antidepressants, antihypertensives, $\beta$-blockers, diuretics, antiarrhythmics, sympathomimetics, parasympathomimetics) that could interfere with the assessment of ANSD, was collected. Control group consisted of 80 subjects recruited from a healthy population. Patient selection disregarded clinical complaints concerning autonomic dysfunction to avoid selection bias. The purpose of the study was explained to both groups and written informed consent was obtained. The local ethical committee approved the study.

\section{Questionnaire}

Owing to the lack of a Portuguese validated questionnaire, we used a still non-validated Portuguese translated version of COMPASS 31 to assess the feasibility of this scale application in evaluating the ANSD in MS population. This questionnaire consisted of 31 questions about different autonomic symptoms, distributed in 6 domains, i.e. orthostatic intolerance (4 items), vasomotor dysfunction (3 items), secretomotor dysfunction (4 items), gastrointestinal dysfunction, combining gastroparesis, diarrhoea and constipation (12 items), bladder dysfunction (3 items) and pupillomotor dysfunction (5 items) (Appendix 1). Scores to each domain were weighted based on their clinical relevance; higher scores indicate more or worse symptoms. The weighted maximum domain score were the following: orthostatic intolerance - 40, vasomotor dysfunction - 5, secretomotor dysfunction - 15 , gastrointestinal dysfunction -25 , bladder dysfunction -10 , and pupillomotor dysfunction -5 . The weighted total score for the instrument ranged from 0 to 100 . Forward and back translations were performed and we attempted to use Portuguese correct linguistic terms understandable to our patients, without changing the meaning of the initial questionnaire.

\section{Approach}

From our initial cohort, two MS patients were excluded because they didn't fill out the whole questionnaire. Then, we analysed ANSD in four groups: a) all MS patients (case group $A, n=103$ ), b) a subgroup of MS patients without confounding factors (case group $B, n=43$ ), c) control group $A(n=80)$ and d) control group B ( $n=43)$, a subgroup of control subjects with subjects selected from the control group A with no statistically significant age and gender differences with MS patients of group B. We determined the frequency of autonomic symptoms in the four groups and compared questionnaire results between all MS patients (case group A) and the control group $A$. We also compared the results obtained in case group B with the control group B.

\section{Statistical analysis}

All statistical analyses were performed using Statistical Package for the Social Sciences (SPSS) version 21. Data were analysed descriptively in terms of means, median and ranges. Mann-Whitney test was used to compare the differences between MS patients and the control group.

\section{RESULTS}

\section{Clinical features of MS and control groups}

Ourstudy included 103 patients (case groupA) with RRMS (71 women (68.9\%), 32 men). Median age was 41 (range 20-61) years and the median disease duration was 6 (range $0-30$ ) years. The degree of disability, expressed by the EDSS score, ranged from 0 to 7 (median 1). Sixty patients (58.3\%) had autonomic function confounding factors such as heart disease or diabetes mellitus, or were on anticholinergics, antidepressants, antihypertensives, $\beta$-blockers, diuretics, sympathomimetics or parasympathomimetics drugs. The remaining group without these confounding factors (case group B) consisted of forty-three MS patients (27 women (62.8\%), 16 men). Median age was 36 (range 20-59) years, the median disease duration was 5 (range 0-30) years and the EDSS score ranged from 0 to 5 (median 1). Case group $A$ and case group $B$ had no statistically significant age and gender differences.

Control group A consisted of 80 healthy subjects (57 women (71.3\%), 23 men) with a median age of 37 (range $20-63$ ) years. We selected 43 subjects (27 women $(71.3 \%)$, 16 men) from the initial control group $A$ as a second control 
group (control group B) with a median age of 37 (range 2053) years (Table 1). Both control groups had no statistically significant age and gender differences with MS patients groups in order to compare ANSD between them.

\section{Autonomic domain scores in MS patients and control groups}

In case group A, one-hundred MS patients (97.1\%) reported alterations in at least one autonomic symptom domain. The percentage of affected subjects, i.e., with a domain score greater than 0 , was as follows: orthostatic intolerance $(60.2 \%)$, vasomotor $(10.7 \%)$, secretomotor (51.5\%), gastrointestinal (89.3\%), bladder (48.5\%), pupillomotor $(84.5 \%)$ (Table 2). Comparison between genders revealed higher scores in women in all domains, with a statistically significant difference in orthostatic intolerance and gastrointestinal domain scores and in the total score $(p<0.05)$.

Forty-one patients of case group B (95.3\%) reported alterations in at least one autonomic symptom domain. The percentage of affected subjects was as follows: orthostatic intolerance $(51.2 \%)$, vasomotor $(7 \%)$, secretomotor $(34.9 \%)$, gastrointestinal (81.4\%), bladder $(20.9 \%)$, pupillomotor (74.4\%) (Table 3).
In the control group A the percentage of subjects with a total score greater than 0 was $96.2 \%$ and in the control group B was $93 \%$. In both control groups, gastrointestinal and pupillomotor domains were the most affected (Tables 2 and 3).

\section{Autonomic domains scores: comparing MS patients and control group}

Comparing to the control group A, MS patients of case group A scored higher in orthostatic intolerance, secretomotor, bladder, gastrointestinal and pupillomotor domains, and lower in vasomotor domain score. The total score was higher in MS patients compared with controls ( $p$ $<0.01$ ) (Table 2).

The MS patients of case group B scored higher in secretomotor domain comparing to the control group $\mathrm{B}$ ( $p<$ $0.05)$. The difference between the other domain scores and total score between these two groups showed no statistical significance (Table 3).

\section{Questionnaire}

The questionnaire was well accepted by the patients, and in spite of the above mentioned two patients, they completed it without difficulties, in approximately 10 minutes.

Table 1 - Clinical features of multiple sclerosis patients and control group

$\begin{array}{cccc}\text { Case Group A } & \text { Case Group B } \dagger & \text { Control Group A } & \text { Control Group B } \\ (n=103) & (n=43) & (n=80) & (n=43)\end{array}$

Gender (m:f)

$\begin{array}{lcccc}\mathrm{n} & 32: 71 & 16: 27 & 23: 57 & 16: 27 \\ \% & 31.1: 68.9 & 37.2: 62.8 & 28.8: 71.2 & 37.2: 62.8 \\ \text { Age (years) } & 41(20-61)^{*} & 36(20-59)^{*} & 37(20-63)^{\star} & 37(20-53)^{\star} \\ \text { Disease duration (years) } & 6(0-30)^{*} & 5(0-30)^{\star} & & \\ \text { EDSS } & 1(0-7)^{*} & 1(0-5)^{\star} & & \end{array}$

${ }^{*}$ Median and range. † Multiple sclerosis patients without confounding factors: heart disease, diabetes mellitus, anticholinergics, antidepressants, antihypertensives, $\beta$-blockers, diuretics, sympathomimetics and parasympathomimetics. MS - multiple sclerosis; EDSS - Expanded Disability Status Scale.

Table 2 - Domain and total scores in patients with multiple sclerosis and control group

\begin{tabular}{|c|c|c|c|c|c|c|c|c|}
\hline \multirow[t]{2}{*}{ Domain } & \multirow[t]{2}{*}{ Max score* } & \multicolumn{3}{|c|}{$\begin{array}{l}\text { Case Group A } \\
\quad(n=103)\end{array}$} & \multicolumn{3}{|c|}{$\begin{array}{l}\text { Control Group A } \\
\qquad(n=80)\end{array}$} & \multirow[t]{2}{*}{$\begin{array}{c}p \\
\text { Value }\end{array}$} \\
\hline & & Median & Range & Affected $\dagger$ & Median & Range & Affected $\dagger$ & \\
\hline Orthostatic Intolerance & 40 & 12.00 & $0-36$ & $62(60.2 \%)^{* *}$ & 8.00 & $0-24$ & $44(55 \%)$ & 0.007 \\
\hline Vasomotor & 5 & 0.00 & $0-3.33$ & $11(10.7 \%)$ & 0.00 & $0-4.17$ & $12(15 \%)$ & 0.365 \\
\hline Secretomotor & 15 & 2.14 & $0-12.86$ & $53(51.5 \%)$ & 0.00 & $0-8.57$ & $19(23.7 \%)$ & 0.000 \\
\hline Gastrointestinal & 25 & 4.46 & $0-16.07$ & $92(89.3 \%)^{\star \star}$ & 3.57 & $0-12.5$ & $70(87.5 \%)$ & 0.049 \\
\hline Bladder & 10 & 0.00 & $0-10$ & $50(48.5 \%)$ & 0.00 & $0-2.22$ & $9(11.2 \%)$ & 0.000 \\
\hline Pupillomotor & 5 & 2.00 & $0-4.67$ & $87(84.5 \%)$ & 2.00 & $0-3.67$ & $71(88.7 \%)$ & 0.053 \\
\hline Total & 100 & 21.35 & $0-66.31$ & $100(97.1 \%)^{* *}$ & 13.34 & $0-44.17$ & $77(96.2 \%)$ & 0.001 \\
\hline
\end{tabular}


Table 3 - Domain and total scores in patients with multiple sclerosis without confounding factors and control group.

\begin{tabular}{|c|c|c|c|c|c|c|c|c|}
\hline \multirow[t]{2}{*}{ Domain } & \multirow[t]{2}{*}{ Max score* } & \multicolumn{3}{|c|}{$\begin{array}{l}\text { Case Group } B^{* *} \\
\qquad(n=43)\end{array}$} & \multicolumn{3}{|c|}{$\begin{array}{l}\text { Control Group B } \\
\quad(n=43)\end{array}$} & \multirow[t]{2}{*}{$\begin{array}{c}p \\
\text { Value }\end{array}$} \\
\hline & & Median & Range & Affected $†$ & Median & Range & Affected $\dagger$ & \\
\hline Orthostatic Intolerance & 40 & 4.00 & $0-28$ & $20(50 \%)$ & 0.00 & $0-20$ & $19(44.2 \%)$ & 0.149 \\
\hline Vasomotor & 5 & 0.00 & $0-1.67$ & $2(5 \%)$ & 0.00 & $0-2.5$ & $3(7 \%)$ & 0.992 \\
\hline Secretomotor & 15 & 000 & $0-10.71$ & $14(35 \%)$ & 0.00 & $0-8.57$ & $6(14 \%)$ & 0.025 \\
\hline Gastrointestinal & 25 & 2.68 & $0-12.5$ & $32(80 \%)$ & 3.57 & $0-10.71$ & $38(88.4 \%)$ & 0.738 \\
\hline Bladder & 10 & 0.00 & $0-5.56$ & $9(22.5 \%)$ & 0.00 & $0-1.11$ & $4(9.3 \%)$ & 0.103 \\
\hline Pupillomotor & 5 & 2.00 & $0-3.33$ & $30(75 \%)$ & 2.00 & $0-3.33$ & $37(86 \%)$ & 0.674 \\
\hline Total & 100 & 13.19 & $0-47.15$ & $38(95 \%)$ & 11.04 & $0-26.90$ & $40(93 \%)$ & 0.204 \\
\hline
\end{tabular}

In general, patients understood and filled out the questions alone but in some cases they needed some help, mainly older patients, patients with motor limitations or difficulties in reading.

\section{DISCUSSION}

In this study we determined the frequency of autonomic symptoms in a cohort of RRMS patients followed in a Outpatients MS Clinic, through the application of a translated version of COMPASS 31 into Portuguese. In general, the questionnaire was easy to administer and understandable to our patients.

We found that the great majority of multiple sclerosis patients $(97.1 \%)$ had changes in autonomic functions, a higher number comparing to earlier studies. ${ }^{7,14,15}$ The percentage of patients complaining about gastrointestinal symptoms was the highest of all domains. This finding supported former studies showing that gastrointestinaldysfunction is a common feature in MS patients, who tend to have slowergastric emptying rate16 as well as bowel symptoms ${ }^{17,18}$ Previous evidence showed that orthostatic intolerance can be present in up to $50 \%$ of MS patients ${ }^{19}$ and in our study it affected around $60 \%$. Furthermore, more than half of the patients from this group had secretomotor symptoms, such as trouble with general body sweating, dry eyes or dry mouth, which is consistent with sudomotor regulation failure found in other studies..$^{20,21}$ Bladder disturbances were also common as expected, since they occur frequently during the course of the disease. ${ }^{18,22}$ These symptoms often cause social embarrassment and may have a severe impact on quality of life. ${ }^{1,5}$ Most of the patients had sensitivity to bright light or trouble focusing their eyes. This pupillary function impairment appears to be affected early in MS. ${ }^{23,24}$ Vasomotor symptoms were rare in this group, with only a small percentage of patients complaining about colour changes in the skin.

Overall, MS patients of case group A showed statistically significant higher scores comparing to the control group A. However, this difference did not remain when patients of case group $\mathrm{B}$, without comorbidities and medications that could interfere with the assessment of ANSD, were compared with a healthy age and gender-matched control group B.

Our study population of MS patients unaffected by confounding factors had a younger age (median 36 years), a lower disability status (median EDSS 1), and importantly, a short disease duration (median 5 years). Previous research analysed the relationship between ANSD and diseaserelated parameters, such as disease disability and disease duration, concluding that patients with a long disease duration rather than high EDSS carried an increased risk of autonomic involvement in MS. ${ }^{7}$ By excluding patients with comorbidities or medications affecting the autonomic nervous system, we excluded a group of older patients with longer disease duration, and this may have contributed to attenuate the differences between the two groups.

We acknowledged that a significant number of healthy control subjects reported alterations in autonomic symptoms domains. As in other studies, this may be to the fact that a full clinical evaluation was not performed, since they were only asked about potential medications or diseases that may interfere with autonomic function.

Furthermore, we have to consider that COMPASS 31 was not designed specifically for MS, thus it is also possible that the questionnaire may not be as sensible to early autonomic dysfunction symptoms as to more severe manifestations. We may also speculate that COMPASS 31 may be more prone to detect autonomic dysfunction due to other diseases, such as diabetes, and medications, than due to MS.

\section{Limitations}

There were some limitations in our study, the main one being the non-validation of the questionnaire in Portuguese language. Furthermore it was hospital based, had a small sample and only included patients with a relapsing-remitting form of MS. We haven't studied the possible correlations between the autonomic symptoms found in our patients with autonomic function tests or with lesion load/localisation 
in brain magnetic resonance imaging. Nevertheless, it deserves to be stressed that this was the first endeavour to apply such a questionnaire in a MS population in our centre.

\section{CONCLUSION}

COMPASS 31 is a simple and practical questionnaire that revealed the presence of autonomic dysfunction in a large proportion of our MS patients, even though we have not found significant differences between MS patients without autonomic function confounders and a group of healthy volunteers. Nevertheless our results are preliminary and additional investigation with a larger sample, patients with different forms of MS and longer disease duration are required to achieve more robust results. Additionally, it would be relevant to correlate the autonomic symptoms found in questionnaire results with autonomic function tests. Further studies are needed to validate this questionnaire and to assess its possible application in MS population in Portugal. In spite of the statistical significance of our results, we believe that the frequency of dysautonomic symptoms in patients with MS in this study should not be undervalued. As such, we suggest health professionals to be mindful of this problem and inquire the patients directly about these symptoms in their patient routine evaluation.

\section{ACKNOWLEDGMENTS}

We thank our colleagues of MS Outpatient Clinic - Jorge Reis, Joana Guimarães, Carlos Andrade, Joana Meireles and our MS patients and healthy volunteers for their collaboration and participation in this study. Without them we could not have done this clinical investigation.

\section{CONFLICT OF INTEREST}

None of the authors have any conflicts of interest to declare.

\section{FUNDING SOURCES}

None stated.

\section{REFERENCES}

1. Adamec I, Habek M. Autonomic dysfunction in multiple sclerosis. Clin Neurol Neurosurg. 2013;115:S73-8.

2. Kale N, Magana S, Agaoglu J, Tanik O. Assessment of autonomic nervous system dysfunction in multiple sclerosis and association with clinical disability. Neurol Int. 2009;16:e5.

3. Adamec I, Bach I, Barušić AK, Mišmaš A, Habek M. Assessment of prevalence and pathological response to orthostatic provocation in patients with multiple sclerosis. J Neurol Sci. 2013;324:80-3.

4. Lensch E, Jost WH. Autonomic disorders in multiple sclerosis. Autoimmune Dis. 2011;2011:803841.

5. Flachenecker P. Autonomic dysfunction in Guillain-Barre syndrome and multiple sclerosis. J Neurol. 2007;255:96-101.

6. Kanjwal K, Karabin B, Kanjwal Y, Grubb BP. Autonomic dysfunction presenting as postural orthostatic tachycardia syndrome in patients with multiple sclerosis. Int J Med Sci. 2010;7:62-7.

7. Gunal DI, Afsar N, Tanridag T, Aktan S. Autonomic dysfunction in multiple sclerosis: correlation with disease-related parameters. Eur Neurol. 2002;48:1-5.

8. Suarez GA, Opfer-Gehrking TL, Offord KP, Atkinson EJ, O'Brien PC, Low PA. The autonomic symptom profile: a new instrument to assess autonomic symptoms. Neurology. 1999;52:523-8.

9. Zilliox L, Peltier AC, Wren PA, Anderson A, Smith AG, Singleton JR, et al. Assessing autonomic dysfunction in early diabetic neuropathy. Neurology. 2011;76:1099-105

10. Mandl T, Granberg V, Apelqvist J, Wollmer P, Manthorpe R, Jacobsson LT. Assessment of autonomic symptoms in diabetics: the Swedish version of the autonomic symptom profile. Clin Physiol Funct Imaging. 2008;28:312-7.

11. Flachenecker P, Reiners K, Krauser M, Wolf A, Toyka KV. Autonomic dysfunction in multiple sclerosis is related to disease activity and progression of disability. Mult Scler. 2001;7:327-34

12. Sletten DM1, Suarez GA, Low PA, Mandrekar J, Singer W. COMPASS 31: a refined and abbreviated Composite Autonomic Symptom Score. Mayo Clin Proc. 2012;87:1196-201.
13. Polman $\mathrm{CH}$, Reingold SC, Banwell B, Clanet M, Cohen JA, Filippi M, et al. Diagnostic criteria for multiple sclerosis: 2010 revisions to the McDonald criteria. Ann Neurol. 2011;69:292-302.

14. McDougall AJ, McLeod JG. Autonomic nervous system function in multiple sclerosis. J Neurol Sci. 2003;215:79-85.

15. Kodounis A, Stamboulis E, Constantinidis TS, Liolios A. Measurement of autonomic dysregulation in multiple sclerosis. Acta Neurol Scand. 2005;112:403-8.

16. el-Maghraby TA, Shalaby NM, Al-Tawdy MH, Salem SS. Gastric motility dysfunction in patients with multiple sclerosis assessed by gastric emptying scintigraphy. Can J Gastroenterol. 2005;19:141-5.

17. Waldron DJ, Horgan PG, Patel FR, Maguire R, Given HF. Multiple sclerosis: Assessment of colonic and anorectal function in the presence of faecal incontinence. Int J Colorect Dis. 1993;8:220-4

18. Hennessey A, Robertson NP, Swingler R, Compston DA. Urinary, faecal and sexual dysfunction in patients with multiple sclerosis. J Neurol. 1999;246:1027-32

19. Flachenecker P1, Wolf A, Krauser M, Hartung HP, Reiners K Cardiovascular autonomic dysfunction in multiple sclerosis: correlation with orthostatic intolerance. J Neurol. 1999;246:578-86.

20. Saari A, Tolonen U, Pääkkö E, Suominen K, Jauhiainen J, Sotaniemi $\mathrm{KA}$, et al. Sweating impairment in patients with multiple sclerosis. Acta Neurol Scand. 2009;120:358-63

21. Saari A, Tolonen U, Pääkkö $E$, Suominen $K$, Pyhtinen J, Sotaniemi KA et al. Sympathetic skin responses in multiple sclerosis. Acta Neurol Scand. 2008;118:226-31.

22. Haensch CA, Jorg J. Autonomic dysfunction in multiple sclerosis. J Neurol. 2006;253:I3-9.

23. Surakka J1, Ruutiainen J, Romberg A, Puukka P, Kronholm E, Karanko $\mathrm{H}$. Pupillary function in early multiple sclerosis. Clin Auton Res. 2008;18:150-4

24. Pozzessere G1, Rossi P, Valle E, Froio CP, Petrucci AF, Morocutti C Autonomic involvement in multiple sclerosis: a pupillometric study. Clin Auton Res. 1997;7:315-9. 


\section{Prevalence of Autonomic Dysfunction in Patients with Multiple Sclerosis}

Acta Med Port 2015:28:51-55

Publicado pela Acta Médica Portuguesa, a Revista Científica da Ordem dos Médicos

Av. Almirante Gago Coutinho, 151

1749-084 Lisboa, Portugal.

Tel: +351218428 215

E-mail: submissao@actamedicaportuguesa.com

www.actamedicaportuguesa.com

ISSN:0870-399X | e-ISSN: 1646-0758

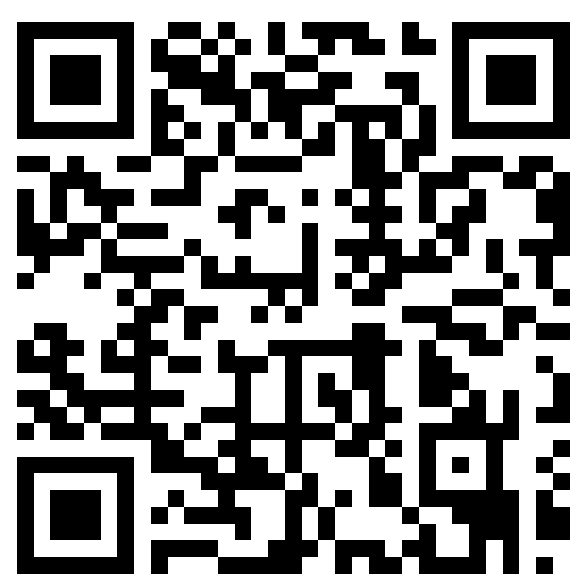

